\title{
Trump: mídia, opinião pública e a espiral do silêncio
}

\author{
Trump: media, public opinion and the spiral of silence
}

\author{
Fernanda Magnotta ${ }^{1}$ \\ Victor Grinberg ${ }^{2}$
}

\begin{abstract}
Resumo: Após o desfecho de uma eleição presidencial histórica que consagrou Donald Trump como $45^{\circ}$ presidente dos Estados Unidos, muitos cientistas políticos voltaram a analisar toda a trajetória da candidatura dos presidenciáveis para entender o que levou as pesquisas de opinião a apontarem um resultado diferente. Nesse sentido, esse trabalho busca explorar os acontecimentos desse pleito desde o lançamento das candidaturas nas primarias, sob a ótica da teoria da espiral do silêncio da Elisabeth Noelle-Neumann e conceitos adjacentes, buscando interpolar o papel da mídia, o perfil do eleitorado e a influência desses fatores na opinião pública desta eleição.
\end{abstract}

Palavras-chave: eleições presidenciais de 2016, mídia tradicional, opinião pública, espiral do silêncio

\begin{abstract}
After a historic presidential election that lead Donald Trump to be 45 th president of the United States, many political scientists analyzed the entire course of presidential candidates' candidacy since the primaries to understand what prompted opinion polls to point to a different outcome. This work seeks to explore the events of this election since the announcement of the candidacies from the perspective of the Elisabeth Noelle-Neumann's spiral of silence theory and adjacent concepts, seeking to interpolate the role of the media, the profile of the electorate and the influence of these factors on the opinion public in the election.
\end{abstract}

Keywords: 2016 Presidential Elections, Traditional Media, Public Opinion, Spiral of Silence

(c) EY Direito autoral e licença de uso: Este artigo está licenciado sob uma Licença Creative Commons. Com essa licença você pode compartilhar, adaptar, para qualquer fim, desde que atribua a autoria da obra, forneça um link para a licença, e indicar se foram feitas alterações. 


\section{Introdução}

Se há algum consenso sobre a eleição presidencial dos Estados Unidos de 2016 é de que ela foi histórica. São vários os motivos que corroboram com essa afirmação. Evidentemente têm a ver com o perfil das candidaturas de Hillary Clinton e Donald Trump - com suas trajetórias e plataformas -, mas também com o contexto de polarização política, desgaste partidário e relativa crise do sistema eleitoral em que se deu a disputa. O pleito foi marcado por uma intensa contraposição entre preferências e visões de mundo, o que revelou uma sociedade dividida e contribuiu para antagonizar grupos de interesses.

Embora a falta de distanciamento histórico ainda não nos permita avaliar com acuidade as implicações do chamado "efeito Trump", há evidências suficientes para dizer que se trata de um fenômeno cujas raízes são profundas e de caráter estrutural. O "trumpismo" tem menos a ver com a persona criada por um presidente per se e muito mais a ver com a manifestação de desequilíbrios e desajustes relevantes que estão no tecido social do país.

Este artigo, de caráter exploratório, tem como objetivo analisar a vitória de Donald Trump à luz da relação entre mídia e opinião pública. Como forma de compreender o resultado das urnas, que apontou em sentido oposto às pesquisas prévias de intenção de voto, pretende-se lançar mão de um modelo emprestado da área de comunicação política: a teoria da espiral do silêncio. A nossa hipótese geral é de que, com a contribuição da mídia, a narrativa anti Trump tornou-se dominante no país, o que teria desencorajado parte do eleitorado a manifestar publicamente seu apoio ao candidato, ainda que efetivamente pretendesse direcionar o seu voto à ele.

Não pretendemos, com isso, sugerir que este tenha sido o fator determinante da eleição. Reconhecemos que esta não é uma abordagem suficiente, mas necessária. Não é suficiente, pois a reviravolta eleitoral também pode ser atribuída a outros fatores, como, por exemplo, à reabertura das investigações de Clinton pelo FBI ou mesmo a baixa capacidade de conversão de votos do partido democrata, sobretudo entre o público mais jovem, já que no país o voto não é obrigatório. Mas, ainda assim, vemos esta como uma abordagem necessária, pois ela ajuda a problematizar os Estados Unidos deste início de século, a partir de um elemento importante: a disputa pelo controle das narrativas e seus efeitos no campo da psicologia social.

\section{Pressupostos teóricos: a espiral do silêncio}

A teoria da "espiral do silêncio" foi originalmente introduzida nos estudos de comunicação política por Elisabeth Noelle-Neumann, em 1974, como tentativa de explicar o comportamento da opinião pública alemã durante a Segunda Guerra Mundial.

O modelo é baseado em algumas premissas. Primeiro, de que as pessoas são sensíveis o suficiente para identificar opiniões dominantes. Por 
meio da observação, elas tendem a classificar padrões de comportamento que são aprovados ou rejeitados na esfera pública. Segundo, de que as pessoas têm medo do isolamento social e sabem identificar as condutas que levam a isso. De acordo com a teoria, há diversos sinais, verbais e não verbais, que sinalizam a possibilidade de "pressão de isolamento". Terceiro, de que as pessoas evitam expressar opiniões que possam levar à crítica ou a sanções sociais, omitindo opiniões polêmicas, adaptando-se ou debandando para opiniões menos conflitivas ${ }^{3}$.

A teoria, portanto, propõe que, diante da controvérsia, os indivíduos tendem a permanecer em silêncio quando sentem que suas opiniões são compartilhadas apenas por uma minoria. Manifestar-se, neste caso, representaria colocar-se à margem da opinião identificada como dominante e, no limite, poderia levar a represálias por parte do grupo. Ao contrário, quanto mais uma pessoa crê que sua opinião é semelhante à opinião prevalecente, mais ela está disposta a divulgar abertamente esta opinião aberta e publicamente 4 .

Ancorado nos estudos de psicologia social, a proposição de Neumann sugere que opiniões sobre temas moralmente ou emocionalmente carregados são particularmente sensíveis à manifestação dos efeitos da espiral do silêncio e que boa parte dos comportamentos coletivos são subconscientes ${ }^{5}$.

Além das interações interpessoais diretas, a teoria coloca no centro do debate a influência exercida pela mídia de massa sobre a opinião pública, já que ela, em alguma medida, centraliza o que será produzido ou reforçado como narrativa dominante. Em termos simples, segundo a teoria, se a mídia repetidamente e de forma consistente apoia um lado em uma controvérsia pública, esse lado terá uma chance significativamente maior de terminar o processo de espiral de silêncio como vencedor ${ }^{6}$.

Ao moldar a opinião pública, a mídia exerceria, portanto, um meio de controle social - o que retoma preocupações de outro grupo de intelectuais dos anos 1970, liderados por Maxwell McCombs e Donald Shaw, que propunham a chamada Agenda-setting theory ${ }^{7}$. Segundo eles, a mídia é ator central no estudo do comportamento social, na medida em que determina a pauta pública ressaltando certos assuntos e preterindo outros. De forma geral, ela guia o consumidor de notícias pelo que passa a ser interpretado como mais importante e/ou como a leitura predominante de uma determinada realidade. Assim, de certo modo, a mídia ajudaria não apenas a moldar a opinião pública do ponto de vista substantivo, mas seria também responsável por manter um alto nível de conscientização sobre o que é considerado consenso social ${ }^{8}$.

Embora a teoria de Neumann tenha sofrido algumas críticas ao longo dos últimos anos, sua hipótese central encontra evidências empíricas significativas. Nos Estados Unidos, particularmente, destacam-se, por exemplo, dois conceitos bem difundidos que corroboram suas premissas: os chamados "efeito Bradley" e "efeito CNN". 
No primeiro caso, trata-se de uma referência à disputa para governador da Califórnia, quando, em 1982, o candidato democrata Tom Bradley perdeu as eleições para o republicano George Deukmejian, mesmo após ter sido considerado favorito pela maioria expressiva das pesquisas de opinião. As distorções no mapeamento de intenção de voto foram atribuídas ao fato de que, muitas vezes, o eleitor responde, diante do agente entrevistador, o que considera 'politicamente correto' ou 'socialmente aceitável' e não o que realmente pensa ou pretende fazer. No caso daquele pleito, em específico, a questão racial pode ter prevalecido. Os indivíduos entrevistados, receosos de serem julgados como racistas por preferirem um candidato branco, teriam omitido sua posição política real. Esse viés impediu que as pesquisas de opinião pública refletissem de forma precisa os resultados das urnas, quando anonimamente eles registraram as suas preferências sem quaisquer filtros ${ }^{9}$.

No segundo caso, trata-se de uma teoria que postula que o desenvolvimento de um canal de televisão como a CNN, com o objetivo de difundir popularmente notícias internacionais 24 horas, causou impacto significativo na percepção da sociedade norte-americana sobre a realidade internacional e o papel dos Estados Unidos no mundo, determinando sua reação a decisões do governo, e no limite, influenciando a condução da política externa do país desde a Guerra Fria. A cobertura exaustiva de um episódio, segundo Steven Livingston, faz com que a mídia, ao mesmo tempo, se torne 1) um ator importante na definição da agenda política, 2) um impedimento para a realização de objetivos políticos desejados e 3) um acelerador para a tomada de decisões políticas ${ }^{10}$.

Considerando o panorama disposto acima e os efeitos que a espiral do silêncio tem na sociedade como um todo, uma das principais hipóteses sobre como Donald Trump consolidou sua imagem e, mais significativamente, as âncoras ideológicas que pautavam sua campanha foram as redes sociais. No contexto do discurso anti Trump na mídia tradicional, que para todos os efeitos pode não representar uma maioria, a única alternativa encontrada foi resignificar a abordagem dando sua impressão dos fatos, sem filtro e, mais importante, criando a retórica de que os conteúdos veiculados por esses emissores eram falsos. Toda essa dinâmica, por sua vez, criou uma grande bolha que permeou o eleitorado e que, de alguma forma, poderia ser apontado um dos indicativos dos custos sociais de se contrapor ao mainstream.

Todos estes conceitos são importantes quando se trata de analisar a eleição de Donald Trump, que, na contramão do que sinalizavam todas pesquisas, tornou-se presidente dos Estados Unidos.

\section{Elementos contextuais: onde tudo começou}

Foi no começo de 2015 que a primeira etapa das eleições presidenciais dos Estados Unidos começou a entoar o desenvolvimento das campanhas que 
perdurariam até o dia da votação em novembro do ano seguinte. Para Hillary Clinton, oficialmente o anuncio da pré-candidatura pelo partido democrata se deu em 12 de abril, embora suas pretensões e ambições políticas para esse pleito fossem conhecidas desde a derrota nas eleições de 2008, quando perdeu a nomeação para Barack Obama. Do outro lado da fronteira partidária, pelos republicanos, o candidato mais surpreendente foi anunciado em 16 de junho, quando o empresário Donald J. Trump lançou seu nome às primárias.

Apesar do favoritismo intrínseco à candidatura de Hillary, vinculado, em parte, ao legado político de seu marido e ex-presidente, Bill Clinton; sua vasta carreira política como senadora por Nova Iorque e Secretária de Estado no governo Obama, ela não teve um passe livre à nomeação democrata, enfrentando nas urnas Bernie Sanders, Senador por Vermont, e Marin O’Malley, ex-governador de Maryland. Apesar de O'Malley ter saído da corrida cedo, ainda em fevereiro de 2016, Sanders pressionou Clinton, atraindo uma demografia chave para essas eleições, os jovens, que viam nas propostas de Sanders uma revitalização nas posições liberais dos democratas, em contraposição a imagem construída de Clinton, associada aos interesses da elite política do país e, consequentemente, distante do americano médio.

Donald Trump, por outro lado, enfrentou um desafio diferente: sua candidatura era uma entre outras 16, majoritariamente políticos de carreira. Enfrentando figuras como Ted Cruz, Senador do Texas, Marco Rubio, Senador da Florida, e Jeb Bush, ex-Governador da Florida, Trump marcou as primárias - e posteriormente seu embate contra Clinton - por falar "a verdade" de maneira crua e direta, sob a égide de ser o único que faria da América grande novamente, em referência ao seu slogan Make America Great Again. Atacando seus opositores e sendo extremamente ativo nas redes sociais, principalmente no Twitter, Trump criou, inclusive dentro do seu próprio partido, uma fissura entre ele e os demais republicanos. Esse paradigma, associado a ataques frequentes à mídia, dominou os ciclos de notícias e criou, nos meios de comunicação, uma cultura anti Trump, como será demonstrado na seção seguinte. Isso, no entanto, não impactou o resultado das urnas e Trump venceu as primárias.

Quando o embate chegou a eleição geral, colocando Clinton e Trump em confronto direto, o já exacerbado papel das mídias se expandiu, gerando milhares de menções diárias, dissecando cada fala, cada postagem e, principalmente, cada escândalo que acometeram os candidatos durante suas campanhas, com ênfase na polêmica envolvendo os e-mails de Clinton. A mídia acabou retroalimentando os exageros de Trump, tornando rotineira a veiculação de seu comportamento, incluindo ataques e desqualificações da oposição.

Essa questão fica clara quando visualizamos a Figura 1, em que a equipe do Projeto GEDLT faz a contagem de menções diária de cada candidato a partir do banco de dados do Television News Archive, que acompanha as principais emissoras: Aljazeera America, Bloomberg, CNBC, CNN, Comedy Central, 
FOX Business, FOX News, LinkTV, MSNBC, além de dezenas das afiliadas locais das principais redes $\mathrm{ABC}, \mathrm{CBS}, \mathrm{NBC}$ e FOX ${ }^{11}$.

Figura 1: Monitoramento de Menções por Candidato (2015-2017)

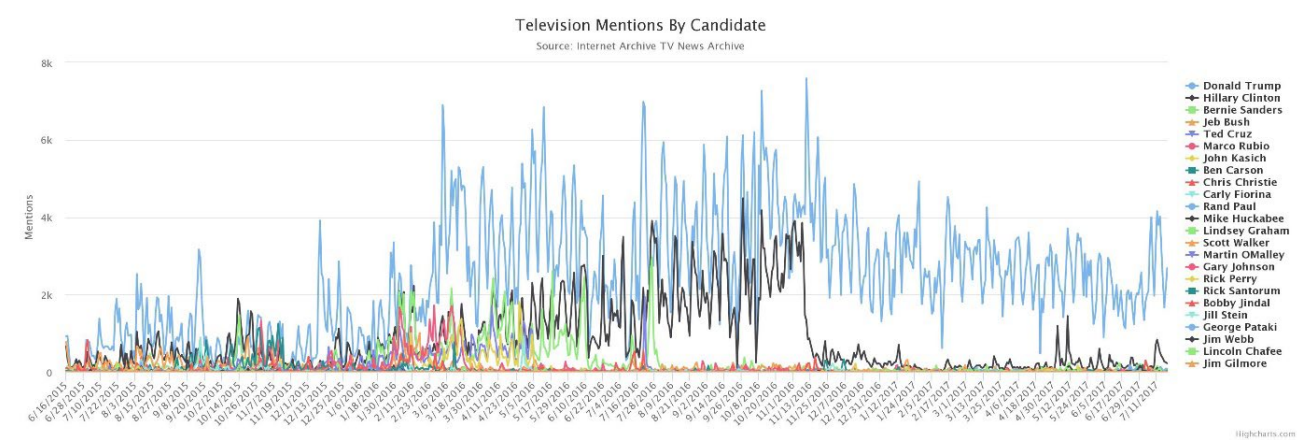

Fonte: GEDLT Project $(2017)^{12}$

Em números absolutos, os dados chamam a atenção quando os candidatos são contrapostos de acordo com a soma gerada pelas respectivas menções, detalhando por emissora. A Figura 2 sinaliza o desequilíbrio da cobertura entre Trump (representado na primeira coluna) e todos os demais concorrentes desde o período de prévias ${ }^{13}$.

Figura 2: Contagem de Menções por Candidato por Emissora (2015-2017)

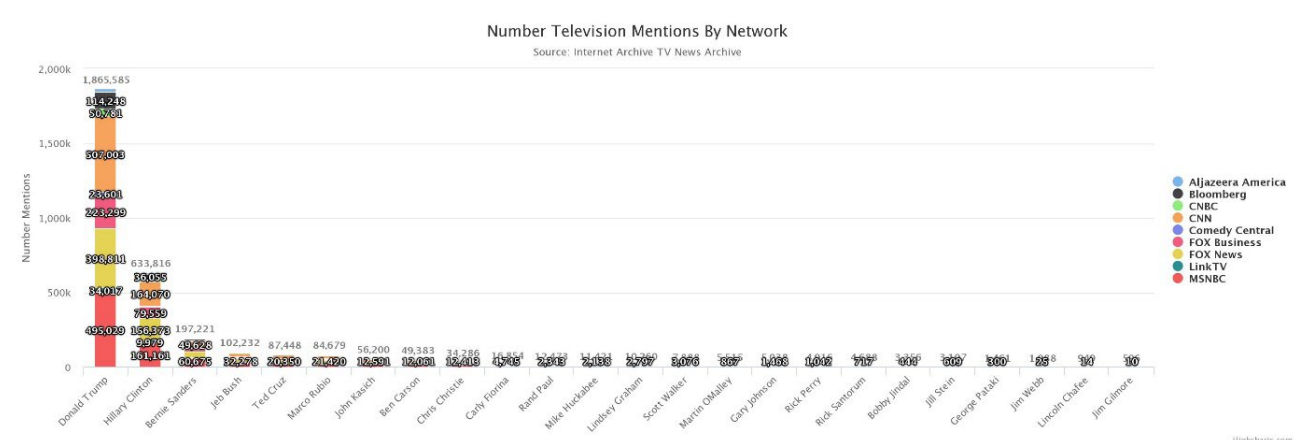

Fonte: GEDLT Project $(2017)^{14}$

Com esse panorama montado, não é possível se desvencilhar do fato que a opinião pública teve um papel importante em todo esse processo. A população era consultada, a cada escândalo, a cada vazamento, a cada ciclo de notícias, e, desde as primárias, o eleitorado foi bombardeado pelos pollsters.

Esse cenário remonta ao que o cientista político Walter Lippmann quis dizer quando sintetizou que o "analista de opinião pública precisa começar reconhecendo a relação triangular entre a cena da ação, a imagem humana daquela cena e a resposta humana àquela imagem sobre a cena da ação”. Indo 
mais a fundo nas teorias de Lippmann sobre o papel da opinião pública no tocante ao papel dos líderes, ele fala:

Devido à sua transcendental importância prática, nenhum líder bem-sucedido jamais esteve tão ocupado em cultivar os símbolos que organizam seus seguidores. O que o privilégio faz dentro da hierarquia, os símbolos fazem aos liderados. Eles conservam a unidade. Do totem à bandeira nacional, do ídolo de madeira ao Deus, o Invisível Rei, da palavra mágica a alguma versão adulterada de Adam Smith ou Bentham, símbolos têm sido apreciados pelos líderes, muitos dos quais foram eles próprios, descrentes, porque eram pontos focais onde as diferenças se fundiam. [...] Mas o líder sabe por experiência que somente quando os símbolos tiverem feito seu trabalho haverá lá um pista que ele poderá utilizar para mover a multidão ${ }^{15}$.

Esse pressuposto ajuda a esclarecer parte da estratégia de Donald Trump para a vitória: ele fez de si o seu próprio símbolo. "Celebridade", "empresário de sucesso", "apresentador de televisão", "dono dos concursos de Miss Universo" são títulos que contribuíram para a criação de uma narrativa específica e ajudaram a reforçar a imagem de que ele era um outsider do mundo da política, próximo ao "homem comum".

Vale ressaltar ainda que a retórica do fake news foi fundamental para que essa imagem fosse consolidada, isso porque os americanos têm uma tendência a desconfiar da mídia tradicional. A Gallup, desde 1997 fez o monitoramento dessa questão, conforme apontado na Figura $3^{16}$ :

Figura 3: Percentual de confiança na mídia de massa, por partido

Trust in Mass Media, by Party

$\%$ Great deal/Fair amount of trust

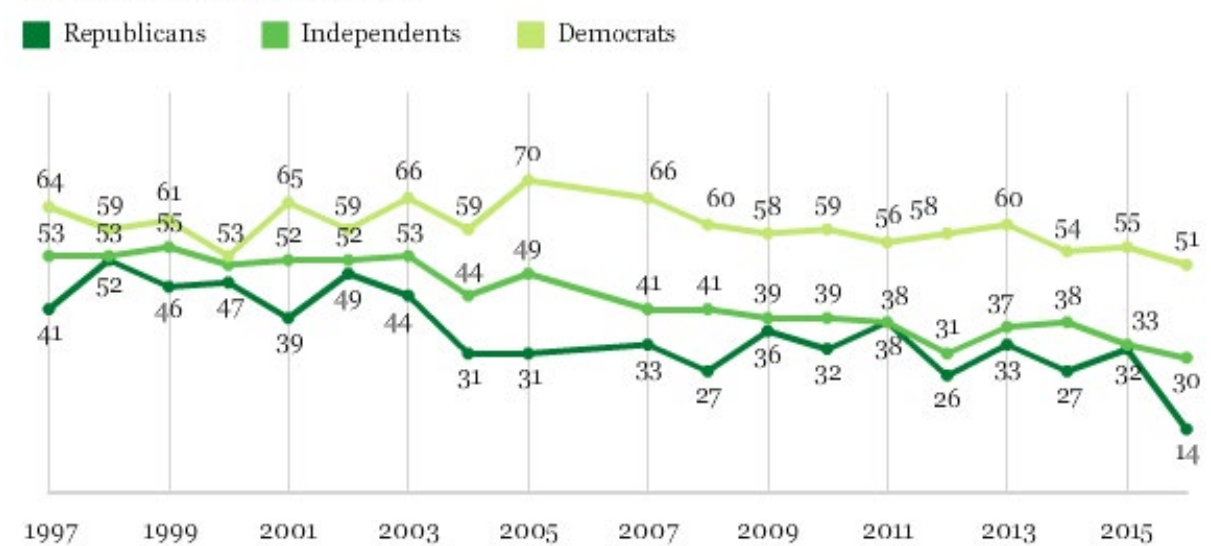

GALLUP 
Detalhado por alinhamento partidário - Republicanos, Democratas e Independentes -, percebe-se o que, para um grupo altamente suscetível ao discurso do fake news, o candidato que se coloca como outsider, bem-sucedido por mérito, interessado na classe trabalhadora e que é alvo da mídia tradicional, acabou soando como perfeito.

\section{Elementos analíticos: mídia, opinião pública e o controle das narrativas}

Durante toda a campanha, os cartazes distribuídos nos comitês republicanos difundiam os dizeres: "a maioria silenciosa está com Trump". O assunto gerou muita especulação sobre os chamados "shy Trump voters", indivíduos que não estariam sendo captados pelas pesquisas, mas que poderiam representar uma surpresa na conversão de votos daquele candidato.

Como já postulamos, a hipótese proposta neste artigo é de que a dificuldade de prever o resultado da eleição presidencial de 2016 pode ser explicada, em alguma medida, pela teoria da espiral do silêncio e seus conceitos adjacentes. Para nós, trata-se de uma abordagem que não é suficiente, mas que é necessária, pois, no caso dos Estados Unidos, capta movimentos importantes do momento de polarização política: a disputa pelo controle das narrativas e seus efeitos no campo da psicologia social.

Segundo relatório do Shorenstein Center on Media, Politics and Public Policy, da escola de governo de Harvard, prevaleceu na cobertura das eleições de 2016 a máxima "más notícias são boas notícias". De acordo com o estudo, a cobertura feita pela mídia teve, em geral, um tom "esmagadoramente negativo" e não privilegiou o debate qualificado de políticas públicas. O relatório mostra que durante o período oficial da eleição geral (de 8 de agosto a 7 de novembro), o viés negativo afetou fortemente os dois candidatos, mas que Trump esteve quase 15 pontos percentuais a frente de Hillary quando o assunto foi a crítica da imprensa. Enquanto ele teve $77 \%$ de cobertura negativa e $23 \%$ de cobertura positiva, Hillary teve $64 \%$ de cobertura negativa e $36 \%$ positiva ${ }^{17}$. Quando são analisadas as coberturas dos debates entre os presidenciáveis, em específico, os dados são ainda mais expressivos, como mostra a Figura $4 .{ }^{18}$

Além disso, de forma geral, Trump recebeu muito menos endossos à sua candidatura do que a oponente. Clinton obteve o apoio de uma longa lista de conselhos editoriais, mais de 240, incluindo os jornais de maior circulação no país, enquanto ele recebeu de apenas 19. Mais do que declarar a preferência por Clinton, vários veículos, inclusive conservadores, chegaram a fazer campanha deliberada contra Trump, advertindo o público sobre os riscos de fazer dele presidente. Até mesmo jornais como The Desert Sun e The Houston Chronicle, que raramente endossam democratas, afirmaram "estar com ela". ${ }^{19}$ 
Figura 4: Tom da cobertura

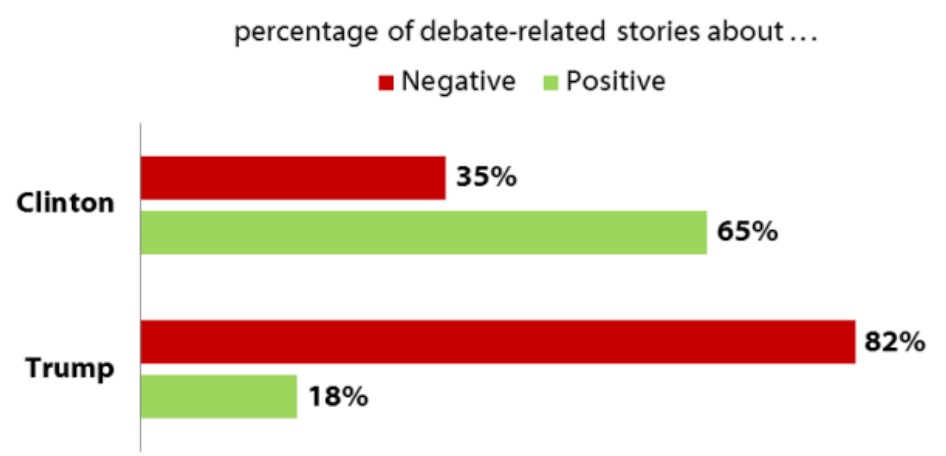

Fonte: Shorenstein Center on Media, Politics and Public Policy.

Conforme apontado anteriormente, devido ao alto índice de desconfiança do americano com a mídia tradicional, o fato desses veículos endossarem Clinton acabou, de certa forma, reforçando aspectos negativos da sua imagem e, na contramão, favorecendo Trump que dialogava diretamente com esse eleitorado que tem aversão à comunicação de massa.

Além disso, tanto jornais grandes como Washington Post e New York Times quanto jornais regionais a exemplo do Des Moines Register e do Arizona Republic fizeram apelos públicos para encontrar colunistas pró-Trump, depois de meses sem conseguir publicar textos que apoiassem a candidatura republicana, dada a escassez de analistas que quisessem se associar a Trump. Como disse Paul Farhi: "os jornais têm muitos escritores conservadores, mas é aí que o problema começa. Trump, que desafiou as categorias tradicionais de esquerda-direita, ofereceu algo que tanto liberais quanto conservadores não gostaram"20.

\section{Figura 5: Tom da cobertura de Trump, por veículo de notícias}

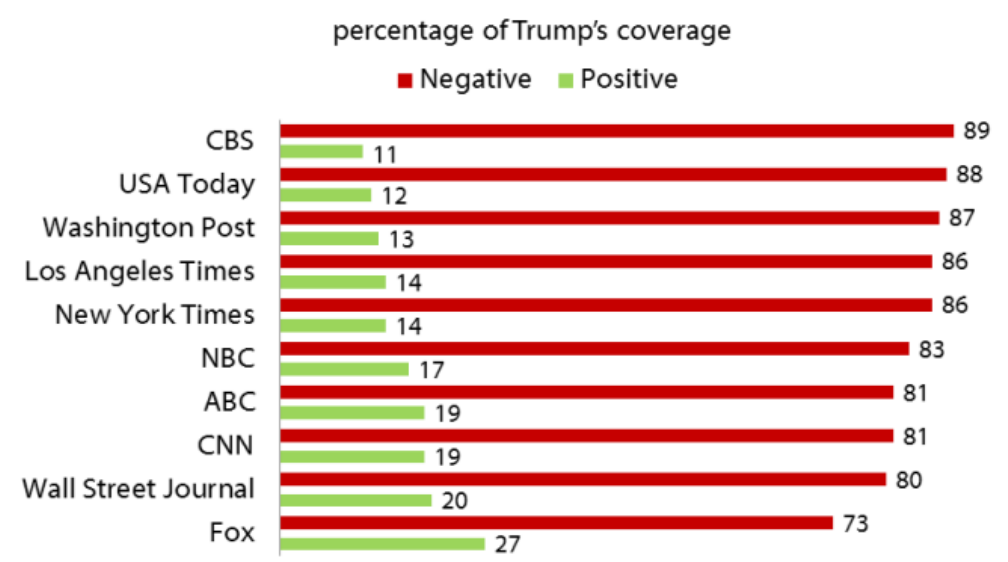

Fonte: Shorenstein Center on Media, Politics and Public Policy. 
A Figura 5 mostra que não apenas na mídia impressa, mas também nos principais veículos de televisão, como CBS, NBC, CNN e mesmo a Fox, usualmente pró republicanos, fizeram uma cobertura predominantemente negativa de sua candidatura. ${ }^{21}$

Outra pesquisa que corrobora com esta avaliação foi feita pela revista The Atlantic em parceria com a Universidade de Vermont. Ao analisar as palavras mais utilizadas pela mídia durante a cobertura das candidaturas, a partir de um banco de dados de cerca de 60.000 artigos publicados entre julho de 2015 e agosto de 2016, a diferença encontrada entre Hillary e Trump é interessante. No caso dela, a shortlist inclui substantivos como "Blackberry", "correspondence", "negligence", "FBI", "investigation" e "Libya" - em referência clara ao uso de um e-mail privado durante seu tempo como Secretária de Estado e a controversa ação coordenada na Líbia durante aquele período. No caso dele, prevalecem os adjetivos: madman, hater, jackass, dummy, sucker e scum. ${ }^{22}$

Todos estes dados reforçam a ideia de que foi construída, no âmbito da mídia, uma narrativa fortemente anti Trump. Isso é relevante, do ponto de vista de nossa análise, pois qualifica o caso para uma avaliação do comportamento do eleitorado à luz da teoria da espiral do silêncio. De acordo com a interpretação de Neumann, as mensagens transmitidas pelos meios de comunicação se fazem relevantes na medida em que são onipresentes, são repetidas exaustivamente e são uniformes ${ }^{23}$. Ao somarmos, portanto, 1) o baixo apoio de veículos, jornalistas e intelectuais à candidatura de Trump e 2) a cobertura majoritariamente crítica de seu pleito, incluindo a contínua adjetivação negativa do candidato, podemos assumir que os custos sociais para apoiar Trump tornaram-se elevados. Em outras palavras, significa dizer que, se a narrativa dominante nas mídias de massa foi identificada como avessa ao candidato, haveria poucos incentivos para que os defensores de uma opinião minoritária se manifestassem publicamente, já que poderiam ser julgados e, no limite, marginalizados socialmente.

Isso fica claro quando nos deparamos com diferentes resultados para pesquisas realizadas online, por telefone e presencialmente. Desde a campanha, pesquisas automatizadas sempre sinalizaram uma melhor avaliação de Trump do que pesquisas tradicionais, feitas com um interlocutor real. De acordo com um levantamento da Five Thirty Eight, a chance de vitória de Clinton chegou a cair mais de 15 pontos quando eram comparadas as versões live e nonlive do levantamento e seus votos no colégio eleitoral oscilaram de 354 para 315. Um padrão que segue sendo verdade mesmo depois que Trump foi eleito. ${ }^{24} \mathrm{De}$ acordo com o POLITICO, no caso desta gestão, "toda vez que o elemento do anonimato é adicionado, as avaliações de aprovação do presidente de repente parecem muito melhores". ${ }^{25}$

Além disso, não se pode ignorar o efeito causado pelas mídias sociais quando o assunto é o controle de narrativas durante esta eleição presidencial. 
Embora elas não tenham sido contempladas na teoria original de Neumann, pois não existiam à época da publicação original do livro, entendemos que podem ser assimiladas como reforços complementares à proposição teórica da espiral do silêncio. Se por um lado é verdade que a Internet trouxe a possibilidade de participar do debate político no anonimato, o que poderia aumentar a tendência de confronto de opiniões a custos sociais relativamente reduzidos, fazendo com que o medo do isolamento fosse minimizado ${ }^{26}$; por outro, lançou os indivíduos em verdadeiras "câmaras de eco", conforme convencionou-se chamar. Isso significa que embora as mídias sociais promovam a ideia de que são plataformas neutras, depositárias de narrativas livres e alternativas ao Agenda-setting típico dos meios de comunicação em massa, elas, por meio dos algoritmos de programação, fazem com que os usuários estejam permanentemente em contato com suas narrativas favoritas, formando grupos polarizados que resistem a informações que não estão de acordo com suas crenças. ${ }^{27}$

Isso dialoga com a teoria da espiral do silêncio por duas razões. Em primeiro lugar, porque, por meio da interação interpessoal, amplia a ideia de opinião pública como um fator de controle social. Em segundo lugar, porque as mídias sociais ao invés de desqualificarem e substituírem as tradicionais mídias de massa, reforçam-nas, muitas vezes, como fontes críveis de informação. Desde a campanha, Trump, como todos sabem, travou uma verdadeira guerra contra a mídia tradicional. Buscando fugir da curadoria dos meios de comunicação, optou pelo diálogo direto com o eleitorado por meio do uso extensivo de redes sociais, sobretudo do Twitter. Cunhou o termo "fake news" e buscou descredibilizar os meios de comunicação mainstream. Poucas semanas após a eleição de Trump, o New York Times registrou um aumento de 132 mil assinaturas pagas em suas versões impressa e digital, dez vezes mais do que no mesmo período do ano anterior e o Wall Street Journal anunciou um aumento de $300 \%$ do número de assinaturas no dia seguinte à eleição. ${ }^{28}$

Além de oferecer alguns insights sobre como a disputa pelo controle das narrativas pode impactar o comportamento do eleitor, a teoria da espiral do silêncio é uma abordagem necessária no contexto de polarização política nos Estados Unidos também no que se refere a captar mudanças relevantes na demografia do voto. Ao revelar a elevada sensibilidade do eleitorado em relação a como será processada e julgada sua opinião, ela pode ajudar a aprimorar as metodologias utilizadas para mapear as intenções de voto ou os interesses da sociedade.

No caso da eleição norte-americana de 2016, antes do pleito, os eleitores de Trump eram estigmatizados pelo "rosto de um homem branco enraivecido". É verdade que, após o resultado, o eleitorado médio do republicano foi identificado como majoritariamente masculino, branco, maior de 40 anos, conservador, morador de subúrbios ou áreas rurais e sem instrução superior $^{29}$. Apesar disso, é fundamental dizer que há grupos importantes que 
impulsionaram a vitória de Trump e que foram subjugados pelo processo político e pelas pesquisas eleitorais. Segundo o The Guardian entre os "shy voters" que levaram Trump à vitória estariam mulheres brancas, por exemplo ${ }^{30}$. De acordo com o levantamento do The Atlantic, Trump foi preferido pelas pessoas que sentem "não ter voz". ${ }^{31}$

De forma geral, as pesquisas desconsideraram o perfil heterogêneo do eleitorado de Trump e as razões específicas que embasavam seus votos. Se Trump foi eleito por membros de seitas religiosas que pregam a soberania branca, também foi eleito pelos afetados pela desindustrialização, pelos que creem em uma agenda econômica de Estado mais enxuto, por aqueles que, apesar de Trump, votaram nele em nome da fidelidade partidária, pelos que tinham interesse em uma agenda social mais conservadora (com foco nas indicações da Suprema Corte), pelos que desconfiavam de Clinton e por um enorme grupo de desiludidos com os políticos do establishment em geral.

Sem surpresa, portanto, uma pesquisa realizada pelo Huffington Post mostra que quando questionados, $51 \%$ dos eleitores de Trump veem a mídia como "inimiga de pessoas como eles", $36 \%$ consideram a mídia pouco amigável e apenas $5 \%$ veem a mídia como uma amiga ou aliada. ${ }^{32}$

É fundamental frisar que não se trata aqui de defender a plataforma de Trump ou de condenar a imprensa, mas de notar que, uma vez que um estereótipo é criado e difundido, ao ser incorporado como narrativa dominante, ele exerce grande poder sobre como as pessoas expressarão ou não as suas opiniões publicamente - de como participarão do debate político, de como serão reconhecidas e analisadas. No caso do eleitorado de Trump, transformar a classe trabalhadora, os chamados blue collars, em caricatura, não só esvaziou o debate, como fez com que os mapeamentos fossem pouco precisos.

\section{Notas}

1 Fernanda Magnotta é Mestre e doutoranda pelo PPGRI San Tiago Dantas (UNESP/UNICAMP/PUC-SP), coordenadora do curso de Relações Internacionais da FAAP e pesquisadora do Núcleo de Estudos e Análises Internacionais (NEAI) e do Núcleo de Estudos sobre a Política Externa dos Estados Unidos (NEPEU). E-mail: fernanda.magnotta@gmail.com

2 Victor Grinberg é Especialista em Mídia, Política e Sociedade pela Fundação Escola de Sociologia e Política de São Paulo (FESP-SP), certificado em estudos de Marketing Digital e professor de Relações Internacionais e Ciências Econômicas da FAAP. E-mail victorgrinberg@hotmail.com.

3 NOELLE-NEUMAN, Elizabeth. The Spiral of Silence: A Theory of Public Opinion. Nova York: Journal of Communication. Jun. 1974. p.43-51. Wiley [online] Disponível em: $<$ http:// onlinelibrary.wiley.com/doi/10.1111/j.1460-2466.1974.tb00367.x/abstract $>$. Acessado em: 20 jul. 2017.

4 Idem.

5 Idem. 
6 Idem.

7 McCOMBS, Maxwell \& SHAW, Donald L. The agenda-setting function of mass media. Public Opinion Quarterly. 1972. no. 36. p. 176-187. Disponível em: <http://www4.ncsu. edu/ amgutsch/Mccombs.pdf $>$. Acessado em: 20 jul. 2017.

8 Idem.

9 PAYNE, Gregory J. The Bradley Effect: Mediated Reality of Race and Politics in the 2008 U.S. Presidential Election. American Behavioral Scientist, v. 54, nov/dez, 2010.

10 LEVINSTON, Steven. Clarifying the CNN effect: An Examination of Media Effects According to Type of Military Intervention. Cambridge: Harvard University. Jun. 1997, 21p. Disponível em: $<$ https://shorensteincenter.org/wp-content/uploads/2012/03/r18 livingston. pdf>. Acessado em: 20 jul. 2017.

11 GDELT Project. 2016 Campaign Television Tracker. GDELT [online]. Disponível em: $<$ http://television.gdeltproject.org/cgi-bin/iatv_campaign2016/iatv_campaign2016>. Acessado em: 20 jul. 2017.

12 Idem.

13 Idem.

14 Idem.

15 LIPPMANN, Walter. Opinião Pública. São Paulo: Editora Vozes. 2a edição. 2010, p. 208.

16 SWIFT, Art. Americans' Trust in Mass Media Sinks to New Low. Gallup [online]. 14 set. 2016. Disponível em: < http://www.gallup.com/poll/195542/americans-trust-mass-mediasinks-new-low.aspx $>$. Acessado em: 20 jul. 2017.

17 PATTERSON, Thomas E. News Coverage of the 2016 General Election: How the Press Failed the Voters. Shorenstein Center [online]. 07 dez. 2016. Disponível em: $<$ https://shorensteincenter.org/news-coverage-2016-general-election/>. Acessado em: 20 jul. 2017.

18 Idem.

19 HARRINGTON, Rebecca; BERKE, Jeremy. Here are all the major newspapers that have endorsed Hillary Clinton for president. Business Insider [online]. 07 nov. 2016. Disponível em: $\quad<$ http://www.businessinsider.com/hillary-clinton-endorsements-newspaper-editorialboard-president-2016-2016-9/\#the-new-york-times-our-endorsement-is-rooted-in-respectfor-her-intellect-experience-toughness-and-courage-over-a-career-of-almost-continuouspublic-service-often-as-the-first-or-only-woman-in-the-arena-1>. Acessado em: 20 jul. 2017.

20 FARHI, Paul. Mainstream media puts out the call for pro-Trump columnists. TWP [online]. 09 dez. 2016. Disponível em: $<$ https://www.washingtonpost.com/lifestyle/style/mainstream-media-puts-out-the-call-for-pro-trump-columnists/2016/12/09/2153fdd2-bca7-11e694ac-3d324840106c story.html?utm term=.4c0e9193b39c >. Acessado em: 20 jul. 2017.

21 PATTERSON, Thomas E. News Coverage of the 2016 General Election: How the Press Failed the Voters. Shorenstein Center [online]. 07 dez. 2016. Disponível em: $<$ https://shorensteincenter.org/news-coverage-2016-general-election/>. Acessado em: 20 jul. 2017.

22 LAFRANCE, Adrienne. 'Scum, 'Madman,' and Other Words Used Most in Trump Coverage. The Atlantic [online]. 02 nov. 2016. Disponível em: $<$ https://www.theatlantic.com/ technology/archive/2016/11/scum-madman-hater-and-other-words-frequently-used-in-coverage-of-donald-trump/506231/>. Acessado em: 20 jul. 2017.

23 NOELLE-NEUMAN, Elizabeth. The Spiral of Silence: A Theory of Public Opinion. 
Nova Iorque: Journal of Communication. Jun. 1974. p.43-51. Wiley [online] Disponível em: $<$ http://onlinelibrary.wiley.com/doi/10.1111/j.1460-2466.1974.tb00367.x/abstract $>$. Acessado em: 20 jul. 2017.

24 ENTEN, Harry. Live Polls And Online Polls Tell Different Stories About The Election. FTE [online]. 31 ago. 2016. Disponível em: $<$ https://fivethirtyeight.com/features/live-pollsand-online-polls-tell-different-stories-about-the-election/>. Acessado em: 20 jul. 2017.

25 SHEPARD, Steven. Donald Trump might be more popular than you think. POLITICO [online]. 02 mar. 2017. Disponível em: < http://www.politico.com/story/2017/02/donaldtrump-popularity-polling-234630>. Acessado em: 20 jul. 2017.

26 HO, S. S., \& McLEOD, D. M. Social-psychological influences on opinion expression in Face-to- face and computer-mediated communication. Communication Research, 35(2), 2008, 190-207.

27 QUATTROCIOCCHI, Walter; SCALA, Antonio; SUNSTEIN, Cass R. Echo Chambers on Facebook. SSRN [online]. 13 jun. 2016. Disponível em: $<$ https://ssrn.com/abstract $=2795110>$. Acessado em: 20 jul. 2017.

28 HUDDLESTON, Tom. The New York Times Has 132,000 Reasons to Thank Donald Trump. Fortune [online]. 02 mar. 2017. Disponível em: $<$ http://fortune.com/2016/11/29/newyork-times-subscribers-donald-trump/>. Acessado em: 20 jul. 2017.

29 GOULD, Skye; HARRINGTON, Rebecca. 7 charts show who propelled Trump to victory. Business Insider [online]. 10 nov. 2016. Disponível em: $<$ http://www.businessinsider. com/exit-polls-who-voted-for-trump-clinton-2016-11/>. Acessado em: 20 jul. 2017.

30 BECKETT, Lois; CARROLL, Rory; FISHWICK, Carmen; JAMIESON, Amber; THIELMAN, Sam. The real 'shy Trump' vote - how 53\% of white women pushed him to victo$r y$. The Guardian [online]. 10 nov. 2016. Disponível em: $<$ https://www.theguardian.com/usnews/2016/nov/10/white-women-donald-trump-victory>. Acessado em: 20 jul. 2017.

31 THOMPSON, Derek. Who Are Donald Trump's Supporters, Really? The Atlantic [online]. 01 mar. 2016. Disponível em: < https://www.theatlantic.com/politics/archive/2016/03/ who-are-donald-trumps-supporters-really/471714/>. Acessado em: 20 jul. 2017.

32 YOUGOV. Huffington Post [online]. fev. 2017. Disponível em: < http://big.assets.huffingtonpost.com/tabsPeopleLikeYou20170220.pdf > . Acessado em: 20 jul. 2017.

Recebido em 17/05/2017

Aprovado em 22/09/2017 